\title{
Creating practice ready, well and professional law graduates
}

\author{
Anneka Ferguson \\ Lecturer, ANU Legal Workshop \\ Australian National University \\ Australia \\ anneka.ferguson@anu.edu.au
}

\begin{abstract}
There is a growing movement to create successful, ethical, well-rounded and practice ready legal professionals both in terms of their content knowledge and their mental well-being. As a Legal Teaching "profession" it is incumbent on us to answer this call in a responsive, creative, integrated, well researched and evaluated manner. This paper provides a suggested and evaluated framework for how this call can be met without resorting to "add on" subjects (no matter how well-intentioned), that stand outside the "normal" law school curriculum. Instead of partitioning well-being and professionalism into separate silos, it is suggested that all efforts must be made to integrate the seeds, thoughts, and actions of ethics, well-being, and professionalism into as many aspects of each of our programs as possible.
\end{abstract}

\section{Keywords}

Legal education, professionalism, simulation, wellness in law, wellbeing in law, integration of professionalism, Giving Voice to Values, Practice Management, online, transactional learning, SIMPLE

\section{Introduction}

There is a growing movement to create successful, ethical, well-rounded and practice ready legal professionals both in terms of their content knowledge and their mental well-being. As a Legal Teaching profession, it is incumbent on us to answer this call in a responsive, creative, integrated, well researched and evaluated manner (Henderson, 2013; Maharg \& Maughan, 2011; Organ, 2011; Stuckey, et al., 2007; Townes O’Brien, Tang, \& Hall, 2011a).

This paper suggests that this call cannot be met by resorting to "add on" subjects (no matter how well-intentioned), that stand outside the "normal" law school curriculum. Instead of partitioning well-being and professionalism into separate silos, all efforts must be made to integrate the seeds, thoughts, and actions of ethics, well-being, and professionalism into as many aspects of each of our programs as possible. As the Carnegie Report (Sullivan, Colby, Welch-Wegner, Bond, \& Schulman, 2007) noted:

The dramatic results of the first year of law school's emphasis on well-honed skills of legal analysis should be matched by similar skill in serving clients and a solid ethical grounding. ... If legal education were serious about such a goal, it would require a bolder, more integrated approach. (p. 4)

This paper will describe and evaluate a how Australian National University Legal Workshop (ANULW) has sought to design and deliver a Professional Legal Education (PLE) program that 
addresses concerns about student well-being, ethical professionalism, and preparedness for the realities of practice by integrating dimensions of ethics, professionalism, and well-being into most activities in the program.

After setting out the context of PLE in the Australian context, this paper examines the four levels of integration required to achieve positive outcomes for our students, including integration between:

- legal practice, educational research and teaching;

- content based legal subject areas and the meta-skills that can assistance in the formation of an ethical and well legal professional;

- teaching and ongoing research evaluation; and,

- the profession and its future professionals, namely, the law students.

This paper will provide examples from the ANU experience to show that transitioning to a more integrated, professionally relevant, and psychologically supportive curriculum is possible. Whilst this change is not necessarily easy or entered into without resistance, it is a model that directly and successfully addresses concerns about student well-being, ethical professionalism, and preparedness for the realities of practice.

\section{Context - Professional legal education (PLE) in Australia}

The PLE component of legal education in Australia takes place after the completion of a four to five year undergraduate (LLB) or three year graduate (JD) law degree. As its name suggests, PLE focuses on the practice of law and therefore pivots away from the predominantly theoretical emphasis of the LLB or JD. At ANULW completing the PLE program results in the conferral of a Graduate Diploma of Legal Practice (GDLP) and meets the prerequisite requirements to be admitted as a legal practitioner in Australia.

ANULW is the largest university-based provider of PLE in Australia. The program has experienced a consistent rise in student enrolments: 2009 - 878; $2010-1,062 ; 2011-1,262 ; 2012$ - 1,557; and 2013 - 2,015. Based on incoming enrolments, ANULW are expecting student enrolments in excess of 2,500 in 2015. Students come from around Australia and internationally with the highest student numbers in NSW and Victoria. The introductory intensive, Becoming $a$ Practitioner, is taught 27 times around Australia each year in all capital cities and some regional centres. In 2012, $61 \%$ of our students were in full time work, $58 \%$ of students worked in a law related area, and $93 \%$ were in paid employment of some sort. Students come from a diversity of backgrounds, 34 law schools, and a variety of workplaces.

In 2010, major curriculum reforms were introduced to the program. This was done in an online learning and simulated practice environment entitled the Professional Practice Core (PPC).

\section{Why simulate and integrate - the case for change}

There is substantial literature to indicate that in many jurisdictions, including the USA and Australia, law school is having a negative impact on the well-being of students.

- In Australia see, Hall, 2009; Hall, Townes O’Brien \& Tang 2010; Larcombe \& Fethers, 2013; Larcombe, Malkin, \& Nicholson 2012; Larcombe, Tubaga, Malkin, Nicholson, \& Tokatlidis, 2013; Townes O’Brien, Tang \& Hall, 2011a, 2011b; and,

- In the USA see, McKinney, 2002; Peterson \& Peterson, 2009; Sheldon \& Krieger, 2007). 
In addition, there is now evidence that many in the legal profession are also continuing to suffer or are developing symptoms and levels of psychological distress at levels higher than that of the comparable general population.

- In Australia see, Kelk, Luscombe, Medlow, \& Hickie, 2009; Beaton Research and Consulting, \& beyondBlue, 2011; Kendall, 2011; and,

- In the USA see, Benjamin, Darling, \& Sales, 1990; Krieger \& Sheldon, 2015; Organ, 2011).

There are now also more resounding calls that law students be better prepared for the realities of being a legal professional by gaining a better sense of professionalism and all that it entails in the legal profession rather than simply "thinking like a lawyer" (Krannich, Holbrook, \& McAdams, 2009; Townes O'Brien, et al., 2011a; Wizner, 1998). Combine this with some of the blows to the legal profession's reputation created by scandals involving lawyers in cases such as Enron in the US (Ackman, 2012) and Australian Wheat Board in Australia (Hall \& Holmes, 2008), and the ever growing concerns that the legal profession is changing or needs to change (Henderson, 2013; Susskind, 2013), and one could be forgiven for thinking that the legal profession is under siege. As part of this siege, the spotlight has to ultimately shift to the education that these future professionals receive at our hands.

PLE in Australia is positioned at a liminal point in students' trajectory from law student to legal practitioner. To make this transition effectively and successfully, students must extend beyond their law student identity and learning expectations and transition to the world of legal practice where many of the indicators of success and support for development are less tangible and definitive. Indeed, the very way of thinking about the law and about the nature of teaching/learning that they are very likely to have been exposed to - namely, thinking like a lawyer in a competitive examination based format - may actually be a part of what is preventing students from becoming the connected, competent professionals that they need to be (Mertz, 2007; Townes O'Brien, 2014).

By necessity, PLE, to be successful, is going to need to disrupt many of the student ways of thinking and study habits that they have established in their undergraduate studies and instead guide them towards developing their own intrinsic professional identity (Maharg \& Maughan, 2011; Stuckey, et al., 2007). As such, it logically follows that the pedagogy cannot follow the traditional model of seminar, lecture, and examination-based assessment. Instead, PLE must engage students with the realities of practice, including legal content and processes, practice management, and professional development. The academy needs to reimagine how legal education could provide this reality check. Within ANULW, this has led to the birth of the PPC (Professional Practice Core).

\section{Transitioning to the professional practice core (PPC) - an integration of educational research and teaching}

Transitioning an entire program curriculum is not successfully done without disruption to the teaching status quo, and to do so successfully, it is important to ensure that the changes are founded on a well-researched base. To this end, the experiential method of delivery of the PPC has been greatly influenced by the SIMPLE project:

SIMPLE (SIMulated Professional Learning Environment) enables students to engage in online simulations of professional practice. Its unique pedagogy is based on transactional learning: active learning through performance in authentic transactions involving reflection in and on learning, deep collaborative learning, and holistic or process learning, with relevant professional assessment that includes ethical standards. 
Also influential was the work of David Boud and Nancy Falchikov (2007) on the creation of sustainable assessment practices that go beyond the academy; the important role of social groupings in creating education outcomes; and how to create successful simulated team learning in an online environment (Jacques \& Salmon, 2008).

Furthermore, this project was not taken on without substantial disruption to the business/teaching model of our institution. Academics/lecturers who had previously had the ability to control their educational domain were required to consider changes to the methods of teaching they felt comfortable with in order to become a part of a larger integrated team of staff that included not only academics with the expertise in the core competency practice areas, but also an educational designer, support staff, IT staff, and third party consultants. This team then used a collaborative and iterative curriculum development approach to develop an innovative and responsive curriculum, combined with an action research approach of planning, action, evaluation, reflection, interpretation and analysis, followed by revised planning (Trevitt, Foley, \& Steed, 2009).

This research and disruption was applied to create the first PPC course. A course that moved the core competencies ${ }^{1}$ of the GDLP from independent, largely decontextualized, traditionally taught units in a hybrid face-to-face or "distance education" model such as recorded lectures, course notes, asynchronous online discussions, independent assessment tasks or exams into one integrated, simulated, and transactional learning environment based on the software and educational pedagogy provided by the SIMPLE project (Barton, McKellar, \& Maharg, 2007; Hughes, Gould, McKellar, Maharg, \& Nichol, 2008).

This PPC learning environment utilises team learning (teams are between three and five in size) and the context of a virtual legal office (Virtual Office Space, (VOS)) to encourage students to develop and practice the skills, attitudes, and professionalism required to be successful in practice. As the PPC aims to provide an authentic simulated legal practice space, it does not include assessment as a series of timetabled, numerically assessed, self-contained assignments, but is a function of completing the transactions to a competent standard on all tasks, that is, a sustainable assessment model (Ferguson \& Lee, 2012).

Experienced legal practitioners are employed as practitioner teachers to mentor and support the student teams. These practitioner teachers provide two functions. Firstly, one group of practitioner teachers provide ongoing feed forward and feedback on all tasks by behaving as the Associates and Senior Partners and clients that the teams encounter in the simulated environment (aka subject mentors). Secondly, another group of practitioner teachers (aka practice mentors) directly mentor students throughout the course on matters pertinent to developing their professional identity, including professionalism, team work, client-focussed service, and practice management skills such as file and risk management.

Furthermore, the PPC is designed to actively engage students in a messy learning process whereby they must discern the nature of their tasks, locate the resources to assist them in resolving the task, and consider that there may not be just one answer to the task provided in order to meet a clients' needs. This also facilitates the embedding of issues pertinent to ethical professional practice (Evans, 2008), conflict, well-being, and mental health issues in real time. It also allows students to explore connections between professionalism and well-being in a safe environment in preparation for the realities of practice that they will soon encounter.

Arguably, this course structure helps to create the students' connections with each other and the profession. The structure also provides the engaging activities that students indicate they would

\footnotetext{
${ }^{1}$ Commercial litigation, property practice, civil litigation, legal practice trust accounting, ethics and professional responsibility and the (newly defined) practice management, as specified by APLEC, the governing body for professional legal education in Australia. See http://www.aplec.asn.au/Pdf/Competency_Standards_for_Entry_Level_Lawyers.pdf for the competency requirements.
} 
like to experience through law school (Townes O'Brien, 2014). For example, students are facilitated to make connections between:

- the theory of the law (as taught at the LLB/JD level) and the practice of law;

- their fellow students, mentors, "simulated" clients, associates and senior partners; and

- themselves and a number of legal practitioners who are already working in the profession.

It is aimed that through this engagement students are able to shape and take control of their own educational/professional development goals in a more satisfying manner.

\section{The role of an integrated practice management component in the PPC}

The integration of the legal content into a simulated environment would not be as effective without functional teamwork and support for the implicit and explicit development of the students' professional identity (Westwood, Rowe, \& Murray, 2012). Thus, the practice management component of the course is used as the blender that integrates the knowledge and application of the law together with the skills and attitudes it takes to transform this knowledge into a successfully legal professional identity.

Beyond the content, practice management is the combination of skills, professional obligations, and qualities that make for a successful practice of and happy interaction with the law (irrespective of the nature of that practice), including development, and promoting professional identity, supporting the development of positive team dynamics and team work skills, supporting the individual, and providing a debriefing space out of the simulated environment that enables appropriate reflection for personal and professional development (Fanning \& Gaba, 2007; Hughes, et al., 2008).

In logistical terms, the practice management component of the PPC is staffed by legal practitioners who are employed as practitioners' teachers to support students in the PPC. These practitioners' teachers are known as "practice mentors" to the students and are allocated to each team of students on a ratio of 1:3-5. Practice mentors support a maximum of six teams of students in each iteration thus ensuring that they are able to meet the needs of their teams on a personal basis whilst also undertaking their other commitments as a legal practitioner.

This concept of practice management has evolved over time. The initial iterations of the PPC in 2010 attempted to transplant the practice management curriculum developed by Westwood and Barton (2006) as part of the SIMPLE project at Strathclyde. This provided a very sound basis for developing this curriculum as it included the fundamentals of mentoring and developing professional identities and teamwork in students.

Each cycle of the course (which occurs twice of year) is permeated with evaluative and reflective practices. As a result, we continually re-evaluate and re-focus our energies on various parts of this curriculum in order to best mentor our students through this integrated but disruptive environment. For example, in 2011, we focussed our training of our mentors and mentoring the cornerstones of professionalism such as courteous, effective, and on-time communications between team members and students and mentors/staff in the PPC. This appeared to have the effect of improving the nature of interactions in all elements of the course, and assisted in lowering the levels of dysfunction and troubling behaviours in teams and by individual students. From our perspective, it was a nicer environment to work in!

\section{The impetus for further change to practice management}

By 2012, apart from the anecdotal evidence that the level of professionalism exhibited by students and staff had improved, we could not tell whether we were successful in our attempts to imbue a sense of professional identity in our students, or whether our changes in curriculum were in fact 
having the desired impact of making rather than breaking our students and future legal professionals in terms of both practice readiness and mental well-being.

Our traditional course satisfaction evaluations across the elements of the course suggested a general level of satisfaction with the practice management component of the course providing students had access to a responsive practice mentor (Darwin \& Knight, 2011). However, these evaluations also suggested that a significant minority of students still viewed some of the practice management activities as an "add on," or irrelevant to their future career and professional development. Furthermore, we could not be sure that we were providing enough support for the students given the disruptive pedagogy we had thrown them into. For example:

Some students were frustrated by the uncertain intent of specific activities in ... [practice management], most notably web conferencing, the reflective processes and the debriefing process. In saying this, it needs to be stressed that equally other students also identified in the earlier portion of the evaluation that they also conversely value all of these activities.

(Darwin, 2011, p. 5)

Accordingly, in keeping with the action research model of curriculum development a few further steps were implemented to address these concerns, namely:

1. further evaluation was required of the best practice research available and the corresponding adjustments to the practice management curriculum these suggested; and,

2. the development of multifaceted integrated evaluation to feed into the ongoing development of the curriculum.

\section{Further research based adjustments to the curriculum}

In addition to the sentiments being expressed in course evaluations, ongoing research into student well-being and preparedness for practice continued to suggest that more attention should be given to developing the students' abilities to deal with the realities of practice. For example, a student's skills and learning should not be limited to dispassionately analysing the law (Townes O'Brien 2014), and analysing esoteric appeal cases in a counterproductively competitive environment. Rather, students should also be able to identify and respond appropriately to: the affect of their clients (Barton, Cunningham, Jones, \& Maharg, 2006; Maharg \& Maughan, 2011); the uncertainty and bounds of their knowledge (Tang, 2011; Tang \& Foley, 2014); how to manage their own practice and communications in order to maximise customer service whilst maintaining their long term well-being and business success (Foley, Holmes Tang, \& Rowe, 2011; Holmes, Foley, Tang, $\&$ Rowe, 2012; how to act on their values and professional obligations (Gentile, 2010); and how to reflect on their practice and experiences to develop professionally.

A combination of this work provided clear recommendations and support for the need to further integrate well-being and professionalism measures into our PLE in order to improve student preparedness for practice. These recommendations, coupled with the curriculum suggestions arising out of the work of Tang (2011) and Gentile (2010), provided a basis for how to turn these principles into actionable learning activities. Once identified, these learning activities were integrated into a single framework and reimagined as an integrated practice management curriculum that built on the established foundations of professionalism, teamwork, and mentoring in order to encourage the development of students' skills in voicing their values and dealing with the uncertainties of practice.

The inter-relationship between these practice management components, the research, and the simulated transactions of the PPC is best demonstrated (simplistically) in Figure 1. 


\begin{tabular}{|c|c|c|c|}
\hline Activity & Observable outputs & Research foundation & Relationship with the simulated transactions \\
\hline Online quiz & Orientation to PPC environment and role of Practice Management & \multirow{4}{*}{$\begin{array}{l}\text { Sullivan, et al. (2007) } \\
\text { Stuckey, et al. (2007) } \\
\text { Barton \& Westwood (2006) } \\
\text { Gentile (2010) } \\
\text { Accepted, evaluated } \\
\text { psychometric testing tools } \\
\text { (Tang \& Ferguson, 2014) }\end{array}$} & Introduce students to the simulated transactional environment. \\
\hline $\begin{array}{l}\text { Online } \\
\text { survey }\end{array}$ & $\begin{array}{l}\text { Student reflection on own values, approaches to conflicts, work management, } \\
\text { professional practice and psychometric testing (voluntary) }\end{array}$ & & $\begin{array}{l}\text { Students with concerning psychometric scores and have "opted in" to be } \\
\text { contacted are contacted by our referring psychologist for support. }\end{array}$ \\
\hline WC \#11 & $\begin{array}{l}\text { Introduction to each other, discussion regarding values and the how to apply } \\
\text { the GVV curriculum through a series of vignettes }\end{array}$ & & $\begin{array}{l}\text { Introduces mentor role to students and supports team creation to ensure } \\
\text { functional collaboration in simulated team work. Outputs include the creation of } \\
\text { a firm agreement and firm team name and logo to be used in all transactions. }\end{array}$ \\
\hline PDJ \#1 & $\begin{array}{l}\text { Tale of Two Stories - Reflection on when students have and have not } \\
\text { expressed their values and why }\end{array}$ & & \\
\hline PDJ \#2 & $\begin{array}{l}\text { Uncertainty Journal - students maintain and reflect on a journal of items they } \\
\text { have been uncertain of over a } 7 \text { day period }\end{array}$ & \multirow[t]{2}{*}{ Tang (2010) } & $\begin{array}{l}\text { Students base these reflections on tasks/situations they find difficult in the } \\
\text { simulation and during their legal practical experience. }\end{array}$ \\
\hline WC \#2 & $\begin{array}{l}\text { Team discussion regarding uncertainty and review of those things you can be } \\
\text { certain of - i.e. team file and time management systems }\end{array}$ & & $\begin{array}{l}\text { Provides a platform for considering emotional responses to uncertainty and } \\
\text { how to support each other as a team to manage risk. }\end{array}$ \\
\hline WC \#3 & $\begin{array}{l}\text { Practising GVV - Speaking to Senior Partner about incorrect claim of legal } \\
\text { privilege }\end{array}$ & \multirow{4}{*}{$\begin{array}{l}\text { Gentile (2010) } \\
\text { Barton \& Westwood (2006) } \\
\text { Accepted, evaluated } \\
\text { psychometric testing tools } \\
\text { (Tang \& Ferguson, 2013) }\end{array}$} & $\begin{array}{l}\text { This is the "other" side of a matter they have been providing ethical advice on } \\
\text { in the simulation }\end{array}$ \\
\hline PDJ\#3 & Reflecting on experience of practising GVV and performance of team members & & \\
\hline $\begin{array}{l}\text { Online } \\
\text { survey }\end{array}$ & $\begin{array}{l}\text { Reflect on any changes in own values, approaches to conflicts, work } \\
\text { management, professional practice and psychometric testing }\end{array}$ & & $\begin{array}{l}\text { Reflecting on experiences from the simulated collaborative environment to } \\
\text { establish a change in students' approach/thinking about the profession. }\end{array}$ \\
\hline WC\#4 & $\begin{array}{l}\text { Practising GVV for well-being-Speaking to a Senior Partner/General Counsel } \\
\text { re wishing to leave the office for the weekend or concerns regarding the mental } \\
\text { health of a colleague. }\end{array}$ & & $\begin{array}{l}\text { Discussing an action framework for well-being at the end of the course, where } \\
\text { we know that students have experienced some mild levels of functional stress } \\
\text { and are very close to being admitted to practice ensures that this discussion } \\
\text { appears relevant and authentic to students. }\end{array}$ \\
\hline $\begin{array}{l}\text { Activity } \\
\text { logs/Work } \\
\text { plans }\end{array}$ & Demonstrate participation in the success of the firm team & $\begin{array}{l}\text { SIMPLE (Hughes, et al. } \\
\text { 2008) }\end{array}$ & $\begin{array}{l}\text { Enable students to practice managing their time and files collaboratively and } \\
\text { individual record all work students have completed for accountability and } \\
\text { communication purposes. }\end{array}$ \\
\hline
\end{tabular}

Figure 1: Relationship between Practice Management components and research

\footnotetext{
${ }^{1}$ In this figure WC stands for Web Conference and PDJ stands for Professional Development Journal.
} 


\section{Integration of Giving Voice to Values}

Giving Voice to Values (GVV) is based on the work by Mary Gentile (2010) ${ }^{1}$ at Babson College in the USA. Initially created for MBA students in relation to business ethics, we have adapted the course to a professional legal education context. The aim of GVV is to help students learn to not just recognise ethical conflicts, but know that they have the skills to act on their values when these conflicts arise. Through concrete examples and practice, GVV encourages self-knowledge and acting from one's own strengths. In so doing, it seeks to promote well-being and preparedness for practice on the working theory that if a practitioner can bring her/his "whole self" to work then she/he will generally have a better sense of well-being and a more sustainable professional identity (Gentile, 2010).

In short, and to paraphrase the much more detailed work of Gentile (2010), the action framework of the GVV curriculum encourages students to:

- $\quad$ understand the scope and limits of general values;

- $\quad$ know that values conflicts will occur;

- $\quad$ become aware of the many common reasons and rationalisations they will receive from others to justify unethical behavior;

- know their own purposes and values; and,

- $\quad$ provide them with the opportunity to practice the skills in order to provide them with the choice to voice their values in conflict situations.

ANULW uses the GVV curriculum in a number of ways throughout the practice management curriculum to build an empowered, assertive, and professional approach to conflict resolution, mentoring, and team development. The particular exercises that have been developed deal with common conflicts that occur in teamwork, in professional ethics, and between personal well-being values and the demands of legal practice.

For example, the first of these exercises examines and practices how to approach circumstances within an online team that may be a result of values conflicts or differing approaches to the way in which work is to be completed. In a meeting with their mentor, students respond to a series of vignettes canvassing common issues experienced in the simulated learning context - i.e., how you respond if you are of the opinion that someone is not completing the allocated work on time, or to a sufficient standard, or not contributing to the work at all. This exercise resonates with students by acknowledging some of the apprehension they may be feeling as they embark on their journey of 18 weeks together as an online team. Accordingly, whilst the scenarios are, for the moment, "not real", the students have a sense that they could be.

The teaching notes to accompany these vignettes encourage the practice mentors to use the scenarios for drawing out discussions that are pertinent to the way in which students will be interacting with each other in the online environment over the 18 weeks, and to explore elements of the GVV curriculum and their own values and work practices. For example, one of the vignettes refers to the situation whereby the student forms the view (inconclusively) that one of the other members of the team has plagiarised in the process of drafting a task that will be submitted as the agreed work of the team. This enables the mentor to discuss the nature of plagiarism with students and the need to adequately proof read and agree on documents for submission. However, the scenario also facilitates a discussion regarding whether you approach the situation with the writer of the work first, or whether you ask questions to ascertain whether it is plagiarism, or accuse them of plagiarism at a specially instituted team meeting, and how these differing approaches may

\footnotetext{
${ }^{1}$ Details of the free GVV curriculum and how to access it can be found at the Giving Voice to Values Curriculum website, BABSON COLLEGE, http://www.babson.edu/Academics/teachingresearch/gvv/Pages/home.aspx
} 
impact on the functionality of the team. And ultimately, by participating in and listening to the responses of their team mates on these issues, each team member can gain an understanding of the diversity of approaches to situations within their team and how these can best be acknowledged to build a functioning team environment.

The curriculum then builds on from these vignette style practices to examine (using surveys and journals), the values and qualities that determine when you choose, and how you choose to act, when your values are conflicted. This culminates, at two further points in the course, in web conferences that further practise and then reflect upon the students' approaches to giving voicing to their values. For example, in web conference 3 this involves holding a conversation with a Senior Partner who has claimed legal professional privilege incorrectly over a document in discover. In web conference 4 this involves either: voicing to your senior partner on a Friday afternoon that you are unable to stay for the weekend to complete non-urgent work as requested; or voicing your concern to a general counsel within a government department that you are concerned about the mental health of a colleague. As with the first web conference, all three of these additional scenarios allows students to both practise how they may approach these uncomfortable and difficult conversations, and also provides an opportunity for the practice mentors to discuss the broader issues of relevance to the successful development of the students' professional identity.

\section{Integration of a curriculum of uncertainty}

In addition to the inclusion of the GVV within our broader practice management curriculum, we also have included exercises and support that recognise the uncertainties of practice that students will encounter on admission. Tang (2011) and Tang and Foley's (2013) research recognises the reality that lawyers practice in an environment saturated with uncertainty, yet at the same time, lawyers find themselves as part of an institution which is imbued with the language of certainty, rules, precedents, and clear-cut results. The clash between these two perspectives without appropriate support and skills to deal with it may in fact be the cause of much early entry lawyer dissatisfaction and/or issues of poor well-being.

Thus, part of the change to the Practice Management curriculum has been about encouraging our students to learn how to be comfortable with recognising and acting positively when confronted with the uncertainties of the legal system. The PPC environment provides the very immediate basis for giving students a sense of the realities of the practice of law, including that such practice can be messy and uncertain. Indeed, students are experiencing uncertainty about their upcoming role as a lawyer, uncertainty about legal content, uncertainty about legal processes, uncertainty about working with other people, and uncertainty about dealing with the real people who are counting on them to develop a legal response that satisfies their emotional needs as well. As such, it also provides the opportunity for assisting students to develop the professional proficiency and knowledge to deal with these aspects of practice.

The curriculum of uncertainty is achieved first through awareness-building through explicitly recognising the forms of uncertainty throughout the course, and then normalising by discussing the uncertainties encountered in as supportive environment. Whilst these discussions are encouraged to occur organically throughout the course, the critical activity involves the keeping of an uncertainty diary over a seven-day period to record and reflect on the uncertainties and their experiences of "non-knowledge." They are then encouraged to reflect on the items they have logged and provide them to their practice mentor for review and comment. In this process, practice mentors don't judge or even provide answers to the uncertainties or the areas of non-knowledge listed by the students. Instead, practice mentors acknowledge how the students are developing the skills to deal with, and feel comfortable with, these uncertainties.

In the accompanying web conference, students and practice mentors are encouraged to pool these areas of uncertainty and workshop possible ways of addressing them. This process allows students to recognise that they are not alone when they feel confused, bewildered, and unsure (i.e., uncertain) about how to proceed, but that they have the skills to find a way through. 


\section{Evaluation}

\section{Quantitative survey}

Since 2012, a quantitative survey has been administered at the beginning and the end of the course We have surveyed almost 2,000 of our students yielding one of the largest and most comprehensive datasets about legal education in Australia. The survey asks about expectations/experiences of the course, indicia of professionalism, management of value and ethical conflicts, and well-being. This is used both as a reflective self-assessment tool by students (that precedes the first web conference students have with their team and practice mentor), and also as an opt-in research tool which allows us to evaluate the effect of the course across different domains. Rigorous psychometric instruments are used to provide the best quality of data in relation to psychological distress/well-being and their possible predictors. ${ }^{2}$

This survey has yielded substantial data about levels of psychological well-being of our students and how this changes at an individual level over the PPC. In stark contrast to high levels of psychological distress consistently found in both US and Australian studies of law students, our results show that students enter the PPC with levels of psychological distress (in terms of depression, anxiety and stress symptoms) at or lower than their community peers. Moreover, this does not change substantially over the course. In other words, despite the intensity of the PPC, our students stay very psychologically healthy (Tang \& Ferguson, 2014).

Indeed, we have accumulating evidence that the focus on professionalism, self-management, and values-congruent experiential learning may be insulating students against sources of distress. This is consistent with the predictions of Self-Determination Theory - that when the basic psychological needs of autonomy, competence, and relatedness are met, well-being can be achieved - which is being explored more explicitly in recent iterations of the survey (Krieger, 2011; Sheldon \& Krieger, 2007).

The survey data also suggests that from the beginning to the end of the PPC students' transition from identifying as law students to identifying as professionals. This is so even though students feel, by the end of the course, that their unknowns will exceed their "knowns" when starting in practice. This result indicates that students might be feeling more comfortable with the idea that the practice of law is uncertain (Tang \& Ferguson, 2013). These early results indicate that it therefore possible to have both a professionally and pedagogically sound curriculum while maintaining the psychological well-being of students.

In relation to the GVV material regarding approaches to conflict, the survey results indicate that, by the end of the PPC, students:

- Both "[u]nderstood that there are costs of voicing values/ethics" and "[u]nderstood that there was a cost of not voicing values/ethics"; and

- $\quad$ Reported they were "[m]ore inclined to ignore/avoid group conflicts rather than address them head on" yet they ideally "[w]anted to voice their ethics/values more often and more effectively" (Internal data).

Both findings highlight the dialectic tension of voicing values and indicate that this is not completely resolved in the PPC material (there is more work to be done!), but suggest that the course seems to make students more mindful and aware of such issues in professional practice.

\footnotetext{
${ }^{2}$ This methodology was reviewed and approved by the ANU Human Research Ethics Committee.
} 


\section{Ongoing debriefing and re-briefing of practice mentors}

With a student cohort of between 700 and 900 students each iteration, and a practice mentor population of between 25 and 35, the legal practitioners we employ as practice mentors are fundamental to student experiences of the curriculum. We know from the course evaluation survey (as distinct from the quantitative survey above), that the enthusiasm and engagement of the practice mentors with both the curriculum and the student teams more generally are critical to the students' perception of the curriculum (Darwin \& Knight, 2011). As such, the debriefing and rebriefing process of these legal practitioners is important to create a successful learning community to support the achievement of the practice management goals. Furthermore, practice mentor opinions about both their experiences of delivering the program, and how the program corresponds with the skills they feel students need in a legal work, are essential to shaping the direction of curriculum.

To capture these opinions we hold web conferences with practice mentors after each set of student web conferences and professional development journals, and at the conclusion of the course - i.e., four times in each iteration of the course ( 8 times a year). The format is an informal dialogue instigated by a several open-ended questions advertised in advance of the meeting - i.e., Did your students struggle with this scenario? Do you think you learnt anything from this scenario? However, the discussion frequently extends beyond the questions so that practice mentors can provide advice to each other about their different approaches and issues arising from the material, and any tips to ensure student engagement. The rough transcriptions of these discussions are then circulated to all practice mentors (even those who had not attended the web conference), for further feedback or corrections to the transcript.

The curriculum design themes that emerged from these discussions included difficulties engaging some students (a minority) with the certain parts of the content or exercises (keeping in mind that, for the most part, students were engaged), and tips on how to adjust scenarios, resources, and delivery of the content in future iterations. Examples were also provided of how the scenarios discussed at these web conferences, and in the professional development journals, were a good springboard for incorporating discussions regarding students' experiences in their own workplaces, and transmitting formative experiences from the legal practitioners own careers. Practice mentors have also commented on the diversity of experiences in the student teams themselves. For example, one practice mentor observed:

\section{Having the mix of industry diversity and experience enabled the younger students to see voicing values in action. ...feedback from students was that the web conference made them think carefully about working in a group beyond the work they had done... [previously].}

The information from the practice mentors is used to strengthen the curriculum in an ongoing fashion. For example, many of the debrief comments from practice mentors on the early running of the GVV scenarios and resources suggested that, whilst students did attempt to engage with the task of planning out their conversation in advance, they did so by writing a word for word script. This approach to preparing for their GVV practise web conference completely flustered students if they encountered an unexpected response from their practice mentor during the web conference. As such, instructions for these web conferences in future iterations referred to the preparation of "dialogue trees" rather than "scripts" to plan out the conversations in advance. Feedback at the subsequent debriefs was that students found this far more useful.

Even with these small difficulties in the practical implementation of the designed curriculum, the general consensus from practice mentors was that the students found the GVV practise useful and could potentially see how it could be used beyond the academy. They reported that the GVV curriculum provided them with a framework in which to mentor students through conflict situations (either within the PPC or the workplace). For example, one practice mentor observed that the scenario for the final web conference involving work hours and well-being "did tie in very nicely with the end of the course - i.e., it was about realities of working in private practice and we used that as a springboard into a discussion about their ... career plans and options". Another 
practice mentor observed that a student who was having problems very similar to one of the GVV scenario problems at their work place had commented "that they thought they might have the words to say something now that they had practised it". Another practice mentor observed that the GVV framework "provides her with a framework to empower students to deal with issues that have arisen within their [PPC] team".

This generally positive characterisation of the curriculum changes also carried through practice mentor discussion about the curriculum of uncertainties. Firstly, they observed that students were really engaging with the task of identifying and diarising their uncertainties. Secondly, practice mentors noticed that students felt a certain amount of comfort from hearing that others were just as uncertain about both the apparently "little" and "big" things encountered in practice or learning in the PPC as they were.

The nature of the uncertainties students were journaling about varied considerably based on student experiences and where they were in their journey towards developing a professional identity. One practice mentor observed that the PDJs they commented on contained "a lot of uncertainties in relation to dealing with supervisors and senior practitioners" which reflected the working public service status of many of the students in her groups. Yet another observed "[a] lot of students expressed uncertainties like "I was worried I wasn't writing enough" ... or "I didn't know how to go about starting a negotiation", which related back to the experiences the students were having in the PPC - i.e., these students did not have the relevant work experience that the other students were drawing upon.

Finally, do these debriefs work as a way of establishing a learning community between the practice mentors themselves? Purely anecdotally, the ongoing attendance by mentors at these voluntary debriefs on a Sunday evening indicates that they are viewed as useful. This view is reinforced when we are able to listen to the many exciting experiences the practice mentors are willing to share. In the words of one practice mentor "I always get ideas from the other practice mentors in these debriefs. It just really does go to show that people are just so different - and, at the end of the day, I think that's a big part of the exercise".

\section{Further evaluative opportunities}

At the end of the course, students are provided with the opportunity to give us permission to review and use their professional development journals for ongoing curriculum evaluation and research purposes. Approximately 5\% of the student cohort agree to this usage of their PDJs on an anonymous basis. Whilst the small opt-in rate for this use of the PDJs does temper any conclusions that can be made from them, evaluating the objectives of the exercises against the outputs from the exercise is to become an essential part of determining whether the exercises are having the impact that we seek.

Similarly, we have also sought permission and interest from students to conduct dialogue-based interviews with them regarding their experiences in the course. Unfortunately we have not had a large take-up of this opportunity - i.e., less than 15 students over the two courses in 2013 . We suspect that this is due to the placement of this aspect at the conclusion of the course - i.e., students are "evaluated out", that is, they begin to suffer feedback fatigue.

The small number of dialogues we have had with students generally indicate a positive reaction to the GVV part of the curriculum with comments such as:

I did have a few value conflicts; I never had a plan or an idea or a focus on how actually these things can be dealt and I was confused and I always thought that you know, it's probably best to leave it.... what PPC may do on the positive side is [give] me some inputs in that I can do something. 
However, a much broader spectrum of students' interviews would be required in order to draw any substantive conclusions, which suggests that a re-evaluation of how to improve participation rates for these interviews should be conducted.

\section{Conclusion}

The gradual revision of the practice management (and indeed overall PPC) curriculum has been based on integrating evidence from the educational, psychological, and organisational literature into a broad simulation of legal practice, rather than as a discrete unit of professional skills. We also depart from established practice to trial novel practices based on sound theory but which had not previously been translated or tested in the legal education context. To ensure that such innovations are indeed helpful, and not useless or harmful, our changes have been backed by qualitative and quantitative evaluations of the course. This nexus between theory, teaching, and empirical evaluation is at the core of ANULW strategy for ensuring we are assisting to turn out graduates who are ready for entrance into the profession. We believe that the lessons learned from our ongoing work ANULW are applicable to law schools in many jurisdictions and can be adapted for traditional, online, large or small teaching settings. In particular, our curricular innovations in the PPC highlight jurisdictionally-unconstrained basic human building blocks which bring together the connections between professionalism and well-being in the practice of law. And most importantly, we have been able to show that we can provide a model of legal education that encourages the development of a professional identity and readiness for practice without distress.

\section{References}

Ackman, D. (2012, January 28). Enron's lawyers: Eyes wide shut? Forbes.com. Retrieved from http://www.forbes.com/2002/01/28/0128veenron.html

Barton, K., \& Westwood, F. (2006). From student to trainee practitioner: A study of team working as a learning experience. 3 Web Journal of Current Legal Issues, Special Issue on Legal Education. Retrieved from http://www.bailii.org/uk/other/journals/WebJCLI/2006/issue3/barton-westwood3.html

Barton, K., Cunningham, C., Jones, G., \& Maharg, P. (2006). Valuing what clients think: standardized clients and the assessment of clinical competence. Clinical Law Review, 13(1), 165 .

Barton, K., McKellar, P., \& Maharg, P. (2007). Authentic fictions: Simulation, professionalism and legal learning. Clinical Law Review, 14(1), 143-193.

Beaton Research and Consulting, \& beyondblue. (2011). Mental health in the workplace. Retrieved from http://www.beatonglobal.com/pdfs/Anxiety_and_depression_in_the_workplace.pdf

Benjamin, G.A., Darling, E.J., \& Sales, B. (1990). The prevalence of depression, alcohol abuse, and cocaine abuse among United States lawyers. International Journal of Law and Psychiatry, 13(3), 233-246.

Boud, D., \& Falchikov, N., (2006). Aligning assessment with long-term learning. Assessment and Evaluation, Higher Education, 31(4), 399-413.

Darwin, S., \& Knight, A. (2011). Evaluation Report. Professional Practice Core: GDLP Integrated Learning Environment, Semester One 2011. Unpublished document, Australian National University, Canberra.

Darwin, S., (2011). Evaluation and Course Development Report Professional Practice Core: GDLP Integrated Learning Environment, Semester Two 2011. Unpublished document, Australian National University, Canberra. 
Evans, A. (2008). Southern exposure: "Post"-liberalism and moral recovery in Australian legal education. The Law Teacher, 42(3), 329-338.

Falchikov, N., \& Boud, D. (Eds.). (2007). Rethinking assessment in higher education: Learning for the longer term. London: Routledge.

Fanning, R., \& Gaba, D. (2007). The role of debriefing in simulation based learning. Society for Simulation in Healthcare, 2(2), 115-125.

Ferguson, A., \& Lee, E., (2012). Desperately seeking... relevant assessment? A case study on the potential for using online simulated group based learning to create sustainable assessment practices. Legal Education Review, 22(1), 121-145.

Foley, T., Holmes, V., Tang, S., \& Rowe, M. (2011). A puppy lawyer is not just for Christmas: Helping new lawyers successfully make the transition to professional practice. Social Science Research Network. doi: 10.2139/ssrn.1956348

Gentile, M. (2010). Giving voice to values: How to speak your mind when you know what's right. London: Yale University Press.

Hall, K. (2009). Do we really want to know? Recognizing the importance of student psychological well-being in Australian law schools. QUT Law and Justice Journal, 9(1), 1-12. Retrieved from https://lr.law.qut.edu.au/article/download/38/37

Hall, K., \& Holmes, V. (2008). The power of rationalisation to influence lawyers' decisions to act unethically. Legal Ethics, 11(2), 137-153.

Hall, K., Townes O’Brien, M., \& Tang, S. (2010). Developing a professional identity in law school: A view from Australia. Phoenix Law Review, 4(19), 19-50.

Henderson, W.D. (2013). A blueprint for change. Pepperdine Law Review, 40(2), 461-507.

Holmes, V., Foley, T., Tang, S., \& Rowe, M. (2012). Practising professionalism: Observations from an empirical study of new Australian lawyers. Legal Ethics, 15(1), 29-55.

Hughes, M., Gould, H., McKellar, P., Maharg, P., \& Nichol, E. (2008). SIMulated Professional Learning Environment - Programme Final Report. Retrieved from http://www.jisc.ac.uk/media/documents/programmes/elearninginnovation/simple_final_report. pdf

Jaques, D., \& Salmon, G. (2008). Learning in groups: A handbook for face-to-face and online environments (4th ed.). London: Routledge.

Kelk, N.J., Luscombe, G.M., Medlow, S., \& Hickie, I.B. (2009). Courting the blues: Attitudes towards depression in Australian law students and lawyers. Brain \& Mind Research Institute, Monograph 2009-1. Sydney, Australia: Brain \& Mind Research Institute.

Kendall, C. (2011). Report on psychological distress and depression in the legal profession. The Council of the Law Society of Western Australia. Retrieved from http://www.mhlcwa.org.au/wp-content/uploads/2013/08/Psychological-distress-depression-inthe-legal-profession-16-May-2011.pdf

Krannich, M., Holbrook, J., \& McAdams, J. (2009). Beyond “Thinking Like a Lawyer” and the traditional legal paradigm: Toward a comprehensive view of legal education. University of Denver Law Review, 86(2), 381-404.

Kreiger, L., \& Sheldon, K. (2015). What makes lawyers happy? Transcending the anecdotes with data from 6200 lawyers. The George Washington University Law Review, 83(2), 554-627. doi: $10.2139 /$ ssrn.2398989

Larcombe, W., \& Fethers, K. (2013). Schooling the blues? An investigation of factors associated with psychological distress among law students. University of NSW Law Review, 36(2), 390436. 
Larcombe, W., Malkin, I., \& Nicholson, P. (2012). Law students' motivations, expectations and levels of psychological distress: Evidence of connections, Legal Education Review, 22(1), 7195.

Larcombe, W., Tumbaga, L., Malkin, I., Nicholson, P., \& Tokatlidis, O. (2013). Does an improved experience of law school protect students against depression, anxiety and stress? An empirical study of wellbeing and the law school experience of LLB and JD students. Sydney Law Review, 35(2), 407-432. Retrieved from http://sydney.edu.au/law/slr/slr_35/slr35_2/407_Larcombe.pdf

Maharg, P., \& Garvey, J. (2010, October). Standardized clients and SIMPLE (SIMulated Professional Learning Environment): Learning professionalism through simulated practice. Paper presented at the Future Ed 2: Making Global Lawyers for the 21st Century conference, Harvard Law School. Retrieved from https://www.slideshare.net/paulmaharg/future-ed-2making-global-lawyers-for-the-21st-century-scs-simple

Maharg, P., \& Maughan, C. (Eds.). (2011). Affect and legal education: Emotion in learning and teaching the law. Surrey, UK: Ashgate.

McKinney, R. (2002). Depression and anxiety in law students: Are we part of the problem and can we be part of the solution? Legal Writing Journal, 8, 229-255.

Mertz, E. (2007). The language of law school: learning to "think like a lawyer". New York: Oxford University Press.

Organ, J. (2011). What do we know about the satisfaction/dissatisfaction of lawyers? A metaanalysis of research on lawyer satisfaction and well-being. University of St Thomas Law Journal, 8(2), 255-274. doi: 10.7206/mba.ce.2084-3356.88

Peterson, T., \& Peterson, E. (2009). Stemming the tide of law student depression: what law schools need to learn from the science of positive psychology. Yale Journal of Health Policy and Ethics, 9(2), 357-434.

Sheldon, K., \& Krieger, L. (2007). Understanding the negative effects of legal education on law students: A longitudinal test of Self-Determination Theory. Personality \& Social Psychology Bulletin, 33(6), 883-897.

Stuckey, R.T., Barry, M., Dinerstein, R.B., Dubin, J.C., Engler, R., \& Elson, J.S. (2007). Best practices for legal education: A vision and a road map. Columbia, SC: Clinical Legal Education Association. Retrieved from http://www.cleaweb.org/Resources/Documents/best_practices-full.pdf

Susskind, R. (2013). Tomorrow's lawyers: An introduction to your future. Oxford: Oxford University Press.

Tang, S. \& Ferguson, A. (2014). The possibility of wellbeing: Preliminary results from surveys of Australian professional legal education students. QUT Law Review 14(1), 27-51. Retrieved from https://lr.law.qut.edu.au/article/view/521

Tang, S. \& Foley, T. (2014). The practice of law and the tolerance of certainty. UNSW Law Journal, 37(3), 1198-1225.

Tang, S. (2011). The practice of law and the intolerance of certainty. Unpublished Masters' Thesis. Australian National University, Canberra.

Townes O’Brien, M. (2014). Connecting law student wellbeing to social justice, problem solving and human emotions. QUT Law Review, 14(1), 52-62. Retrieved from https://lr.law.qut.edu.au/article/view/514

Townes O’Brien, M., Tang, S., \& Hall, K. (2011a). No time to lose: Negative impact on student wellbeing may begin in year one. International Journal of the First Year in Higher Education 2(2), 49-60. doi: 0.5204/intjfyhe.v2i2.84 
Townes O’Brien, M., Tang, S., \& Hall, K. (2011b). Changing our thinking: empirical research on law student wellbeing, thinking styles and the law curriculum. Legal Education Review, 21(2), 149-182.

Trevitt, C., Foley, T. \& Steed, A. (2009). Curriculum (re)development “on the job" in higher education: Benefits of a collaborative and iterative framework supporting educational innovation. International Journal of Innovation in Education, 1(1), 35-50.

Westwood, F., Rowe, M., \& Murray, M. (2012). Professionalism in pre-practice legal education: An insight into the universal nature of professionalism and the development of professional identity. The Law Teacher, 46(2), 120-131.

William M. Sullivan, W., Colby, A., Welch-Wegner, J., Bond, L., \& Schulman, L. (2007). Educating lawyers: Preparation for the profession of law. Carnegie Foundation for the Advancement of Teaching. San Francisco, CA: Jossey-Bass.

Wizner, S. (1998). Is learning to “Think Like a Lawyer" enough? Yale Law and Policy Review, 17, 583-592.

\section{Acknowledgement}

The author gratefully acknowledges the support and advice from the following people of ANU Legal Workshop, Australian National University: Associate Lecturer, Stephen Tang, who has provided support and advice in preparing this paper, the online survey and data analysis upon which much of this work relies; the leadership of our Director, Gary Tamsitt in providing the environment for both the pedagogy and research in this article; Senior Lecturer, Vivien Holmes, for her championing of, input into, and guidance on the Giving Voice to Values curriculum; and, to all the other colleagues and students, too numerous to mention, who have been along for the ride.

Copyright @ 2015 Anneka Ferguson 